\title{
INVERSE RELATIONSHIP BETWEEN ADHERENCE TO THE MEDITERRANEAN DIET AND SERUM CYSTATIN C LEVELS
}

\author{
Natalia G. Vallianou', Ekavi Georgousopoulou², Angelos A. Evangelopoulos ${ }^{1}$, Vassiliki Bountziouka², Maria S. \\ Bonou', Evangelos D. Vogiatzakis ${ }^{1}$, Petros C. Avgerinos ${ }^{1}$, John Barbetseas ${ }^{1}$, Demosthenes B. Panagiotakos ${ }^{2}$ \\ ${ }^{1}$ Evangelismos General Hospital, Athens, Greece \\ 2Department of Nutrition and Dietetics, Harokopio University of Athens, Athens, Greece
}

\section{SUMMARY}

Objective: The aim of the present study was to examine serum cystatin C levels in association with the Mediterranean diet in a healthy Greek population.

Methods: Cystatin C together with basic clinical chemistry tests was measured in a total of 490 adults ( $46 \pm 16$ years, $40 \%$ of males), who underwent an annual health check. Demographic, anthropometric and lifestyle characteristics were recorded, while adherence to the Mediterranean diet was evaluated through the MedDietScore (0-55).

Results: The mean level of serum cystatin C was $0.84 \mathrm{mg} / \mathrm{L}$, while men had increased serum cystatin C levels compared to women $(0.86 \mathrm{mg} / \mathrm{L}$ vs. $0.83 \mathrm{mg} / \mathrm{L}$, respectively, 0.017 ). After adjusting for age, gender, body mass index, smoking status, hypertension, diabetes, hypercholesterolemia, estimated glomerular filtration rate (eGFR), albumin and ferritin levels, each unit increase in MedDietScore led to $0.002 \mathrm{mg} / \mathrm{dL}$ drop off in cystatin $\mathrm{C}$ serum levels.

Conclusions: We have demonstrated an inverse relationship between the MedDietScore and serum cystatin $\mathrm{C}$ levels. Our finding that increases in MedDietScore are associated with decreases in serum cystatin $\mathrm{C}$ levels could imply that adherence to the Mediterranean diet may reduce the cardiovascular risk, as assessed by cystatin $\mathrm{C}$, a prognostic marker of the cardiometabolic risk. This notion could have a great impact on public health.

Key words: cystatin C, MedDietScore, Mediterranean diet, cardiovascular risk

Address for correspondence: N. Vallianou, Evangelismos General Hospital, $45-47$ Ipsilantou str 10676, Athens, Greece. E-mail: natalia.vallianou@hotmail.com

https://doi.org/10.21101/cejph.a4786

\section{INTRODUCTION}

Cystatin C is a non-glycosylated, low molecular weight (13.250 Da), basic protein that is a member of the cystatin superfamily of cysteine protease inhibitors (1-3). It consists of 120 amino acids, it is produced by all nucleated cells at a constant rate, and it is excreted by the kidneys by free glomerular filtration and complete tubular reabsorption and degradation (4-6). Besides its usefulness as a marker of renal function, serum cystatin C appears to be a prognostic marker of cardiovascular events and death among elderly persons without chronic kidney disease (7, 8). The association of serum cystatin $C$ with chronic low-grade inflammation and atherosclerosis has been proposed as the causal link between increased cystatin $\mathrm{C}$ concentrations and adverse cardiovascular outcomes (9).

As widely known, dietary habits play a critical role in the pathogenesis of atherosclerosis. The present study aimed to explore whether there is an association between the Mediterranean diet and the serum levels of cystatin $\mathrm{C}$, as a marker of increased cardiovascular risk.

\section{MATERIALS AND METHODS}

\section{Subjects}

Between April 2009 and January 2010, a total of 490 consecutive adults ( $46 \pm 16$ years, $40 \%$ of men) who had visited the Polyclinic of General Hospital for a health check-up, agreed to participate in the study ( $85 \%$ of participation rate). The retrieved data were confidential and the study followed the ethical considerations provided by the World Medical Association (52nd WMA General Assembly, Edinburgh, Scotland, October 2000). Moreover, the Institutional Review Board approved the design, procedures and aims of the study (GA 23/14.05.2009). All participants were informed about the procedures of the study and agreed to participate providing written informed consent.

\section{Lifestyle and Anthropometric Measures}

All the participants were Caucasians. Information on age (years), gender (males vs. females), level of education (years 
of school) and family status (singles, i.e. single, divorced, widowed, vs. married) were recorded in a self-administrated questionnaire.

With respect to lifestyle characteristics, participants were asked to fill in a 10-grade scale range regarding their physical activity status (grade of scale used: 1-10, where 1 denotes sedentary lifestyle and 10 daily hard activity of at least 30 minutes). Participants with score $\leq 7$ were classified as of low/moderate activity, while those with score $>7$ were considered as highly active. Current smoking was defined as smoking at least 1 cigarette/day for the past year. The number of cigarettes per day and the total years of smoking were also recorded. A 76-item valid semi-quantitative Food Frequency Questionnaire (FFQ) was used to record participants' dietary habits (10). Alcohol consumption was then assessed as the number of drinks per day measured in equivalences of ethanol intake. Furthermore, overall assessment of dietary habits in terms of adherence to the Mediterranean dietary pattern was evaluated through the MedDietScore (range 0-55) (11). Higher values of the score indicate greater adherence to this pattern and, consequently, healthier dietary habits. More specifically, one unit increase in MedDietScore could reflect small dietary modifications such as consumption of 1 more fish serving per week, 3 more fruits per week, or consumption of 1 less portion of red meat per week. The top score of MedDietScore (i.e. 55) depicts the strongest adherence to the Mediterranean diet which consists of more than 4 portions of non-refined cereals per day, more than 5 potatoes a week, 3 fruit and 4 vegetables portions a day, more than 6 fish and legumes servings per week, and everyday use of olive oil in cooking. Moreover, the highest score includes moderate alcohol intake, modest consumption of full-fat dairy (less than 10 servings per week) and poultry (maximum 3 portions per week), while red meat intake should not exceed 1 serving per week.

Waist circumference and height were measured to the nearest $0.5 \mathrm{~cm}$, without shoes, and weight was measured with a lever balance to the nearest $100 \mathrm{~g}$ without shoes in light undergarments. Body mass index (BMI) was calculated as weight in kilograms divided by the square of height in metres. Participants were classified as overweight if BMI was between $25-29.9 \mathrm{~kg} / \mathrm{m}^{2}$, while obesity was defined as BMI greater than $29.9 \mathrm{~kg} / \mathrm{m}^{2}$.

Systolic and diastolic blood pressure was measured twice in all participants by the same physician using a standard mercury sphygmomanometer on the right arm of the seated subject. The mean value for blood pressure measurements was adopted. Hypertension was thus defined as a systolic blood pressure $\geq 140$ $\mathrm{mmHg}$ and/or a diastolic blood pressure $\geq 90 \mathrm{mmHg}$ or the use of anti-hypertensive drugs. Coronary heart disease, heart failure, cerebrovascular disease, and peripheral arterial disease were assessed by self-report and medication use. Diabetes was assessed by self-report, medication use or a positive diagnosis by fasting blood glucose level ( $\geq 126 \mathrm{mg} / \mathrm{dL}$ ) (12). Hypercholesterolemia was defined as a serum cholesterol $\geq 200 \mathrm{mg} / \mathrm{dL}$ or by the use of cholesterol-lowering drugs.

\section{Laboratory Parameters}

Venipuncture was performed for each participant early in the morning (between 7 a.m. to 11 a.m.), after a 12-hour fasting period by applying a natural latex rubber strap and using a $20 \mathrm{~mL}$ syringe. Reproducibility in the lab has been determined using human samples and controls in an internal protocol. For the above mentioned tests, within run and between day coefficients of variation $(\mathrm{CV})$ were less than 7\%. Accuracy of results was further supported by participation in suitable external quality assurance programmes (ESEAP). All measurements were performed on a Roche/Modular Analytics analyzer. Reagents, calibrators, controls, and consumables were purchased from the same supplier (Roche Diagnostics GmbH, Mannheim, Germany).

\section{Statistical Analysis}

Continuous variables are presented as mean values \pm standard deviation under the normal distribution hypothesis and median (1st, 3rd quartile) for not normally distributed continuous variables. Categorical variables are presented as frequencies (relative frequencies). Independent samples t-test, or the nonparametric Mann-Whitney U-test were used in the unadjusted analyses (where appropriate). Multiple regression analyses were performed in order to test the associations between the MedDietScore and serum levels of Cystatin C, after controlling for several confounders in three nested models. Results are presented as Beta coefficients. All reported p-values are based on two-sided tests and compared to a significance level of 5\%. SPSS 18.0 software (SPSS Inc. 2004, Chicago, Illinois, USA) was used for all statistical calculations.

\section{RESULTS}

The mean level of serum cystatin $\mathrm{C}$ was $0.84 \mathrm{mg} / \mathrm{L}$, while men had increased serum cystatin $\mathrm{C}$ levels compared to women $(0.86 \mathrm{mg} / \mathrm{L}$ vs. $0.83 \mathrm{mg} / \mathrm{L}$, respectively, 0.017). The mean level of adherence to the Mediterranean diet was moderate (i.e. 30/55 as assessed using the MedDietScore), but it was at the same level for both genders $(p=0.329)$. The socio-demographic and clinical characteristics of the participants are presented in Table 1, in respect to their gender.

As presented in Table 1, men had significantly higher Body mass index than women, higher waist circumference, higher systolic and diastolic blood pressure, higher serum glucose levels, higher serum triglycerides levels, higher cystatin $\mathrm{C}$ levels, higher serum albumin levels, and higher ferritin levels, while they had lower HDL-cholesterol levels and lower glomerular filtration rate (GFR) than women. In order to better evaluate the effect of adherence to the Mediterranean Diet on cystatin $\mathrm{C}$ serum levels three nested models adjusted for several socio-demographic and clinical characteristics were performed (Table 2).

After adjusting for age, gender, body mass index, and smoking status, each unit increase in the MedDietScore led to 0.003 $\mathrm{mg} / \mathrm{dL}$ reduction of cystatin $\mathrm{C}$ levels (Model 1). After further adjustment for the presence of hypertension, diabetes and hypercholesterolemia, each unit increase in the MedDietScore led to a $0.003 \mathrm{mg} / \mathrm{dL}$ decrease of cystatin C levels (Model 2). In the final model (Model 3), three more confounding factors were taken into account (i.e. GFR, albumin and ferritin levels). Even in this model, each unit increase in the MedDietScore led to $0.002 \mathrm{mg}$ / dL drop off in cystatin C serum levels (Model 3). 
Table 1. Socio-demographic and clinical characteristics of the participants in respect to their gender $(N=490)$

\begin{tabular}{|c|c|c|c|}
\hline Characteristic & Men $(n=296)$ & Women $(n=194)$ & $\mathrm{p}$ \\
\hline Age (years) & $47 \pm 16$ & $46 \pm 16$ & 0.342 \\
\hline MedDietScore (0-55) & $30 \pm 4$ & $30 \pm 4$ & 0.329 \\
\hline Body Mass Index $\left(\mathrm{kg} / \mathrm{m}^{2}\right)$ & $28 \pm 4$ & $26 \pm 5$ & $<0.001$ \\
\hline Waist circumference (cm) & $99 \pm 12$ & $87 \pm 13$ & $<0.001$ \\
\hline Systolic blood pressure (mmHg) & $123 \pm 17$ & $116 \pm 19$ & $<0.001$ \\
\hline Diastolic blood pressure $(\mathrm{mmHg})$ & $77 \pm 11$ & $72 \pm 11$ & $<0.001$ \\
\hline Glucose (mg/dL) & $101 \pm 18$ & $94 \pm 16$ & $<0.001$ \\
\hline Total cholesterol (mg/dL) & $200 \pm 43$ & $200 \pm 38$ & 0.612 \\
\hline HDL-cholesterol (mg/dL) & $43 \pm 11$ & $55 \pm 14$ & $<0.001$ \\
\hline LDL-cholesterol (mg/dL) & $130 \pm 39$ & $127 \pm 34$ & 0.257 \\
\hline Triglycerides (mg/dL) & $118(82,161)$ & $80(59,116)$ & $<0.001^{*}$ \\
\hline C-reactive protein (mg/dL) & $0.10(0.10,0.20)$ & $0.10(0.00,0.28)$ & $0.755^{*}$ \\
\hline Cystatin C (mg/dL) & $0.86 \pm 0.16$ & $0.83 \pm 0.16$ & 0.017 \\
\hline Glomerular Filtration Rate (mL/min) & $102 \pm 18$ & $107 \pm 20$ & 0.016 \\
\hline Albumin (g/dL) & $4.8 \pm 0.28$ & $4.6 \pm 0.28$ & $<0.001$ \\
\hline Ferritin (ng/dL) & $128 \pm 90$ & $65 \pm 80$ & $<0.001$ \\
\hline
\end{tabular}

Continuous variables are presented as mean \pm standard deviation when normally distributed (and median (1st ,3rd quartile)); p-values obtained from independent samples: $\mathrm{t}$-test under the normal distribution hypothesis (and Mann-Whitney non parametric test if normality was not satisfied)

Table 2. Nested multivariate linear regression models evaluating the role of adherence to the Mediterranean Diet in serum levels of Cystatin C

\begin{tabular}{|l|c|c|c|}
\hline \multirow{2}{*}{ Characteristic } & \multicolumn{2}{|c|}{ Beta $(95 \%$ Cl) } & Model 2 \\
\cline { 2 - 4 } & Model 1 & $0.005(0.004,0.006)$ & $0.001(0.000,0.002)$ \\
\hline Age (years) & $0.005(0.004,0.006)$ & $0.024(-0.003,0.050)$ & $0.005(-0.013,0.022)$ \\
\hline Gender (male vs. female) & $0.023(-0.004,0.049)$ & $-0.003(-0.006,0.000)$ & $-0.002(-0.004,0.000)$ \\
\hline MedDietScore (per 1 unit out of 55) & $-0.003(-0.007,0.000)$ & $0.001(-0.002,0.004)$ & $0.000(-0.002,0.002)$ \\
\hline Body Mass Index (per 1 kg/m²) & $0.001(-0.002,0.004)$ & $0.043(0.016,0.071)$ & $-0.012(-0.028,0.005)$ \\
\hline Smoking (yes vs. no) & $0.040(0.013,0.068)$ & $0.037(0.004,0.071)$ & $0.004(-0.015,0.023)$ \\
\hline Hypertension (yes vs. no) & - & $-0.020(-0.071,0.031)$ & $0.004(-0.025,0.033)$ \\
\hline Diabetes (yes vs. no) & - & $-0.034(-0.061,-0.006)$ & $-0.012(-0.029,0.005)$ \\
\hline Hypercholesterolemia (yes vs. no) & - & - & $-0.007(-0.007,-0.006)$ \\
\hline Glomerular filtration rate (per 1 mL/min) & - & - & $-0.023(-0.055,0.010)$ \\
\hline Albumin (per 1 g/dL) & - & - & $0.000(0.000,0.000)$ \\
\hline Ferritin (per 1 ng/dL) & - & - & \\
\hline
\end{tabular}

Betas estimated through linear regression models

\section{DISCUSSION}

In this study, we observed an inverse relationship between adherence to the Mediterranean diet and serum cystatin $\mathrm{C}$ levels after adjustment for age, gender, body mass index, smoking habits, hypertension, diabetes, and hypercholesterolemia. In other words, adherence to the Mediterranean diet was associated with lower serum cystatin $\mathrm{C}$ levels.

Cystatin $\mathrm{C}$ is produced by all nucleated cells at a constant rate, and it is excreted by the kidneys by free glomerular filtration and complete tubular reabsorption and degradation $(13,14)$. Therefore, serum concentration levels of cystatin $\mathrm{C}$ are almost totally depend- ent on the glomerular filtration rate and even a slight reduction in glomerular filtration rate causes a rise in serum cystatin $\mathrm{C}(15,16)$. Besides its usefulness as a marker of renal function, serum cystatin C appears to be a prognostic marker of cardiovascular events and death among elderly persons without chronic kidney disease (17, 18). In recent years, cystatin $C$ has emerged as a potential marker for cardiovascular risk $(18,19)$. A plausible link between increased cystatin $\mathrm{C}$ concentrations and adverse cardiovascular outcome apart from renal failure could be chronic inflammation such as atherosclerosis. Indeed, high serum cystatin $\mathrm{C}$ concentrations have been documented to be associated with high concentrations of hs-CRP and monocytes count in blood $(20,21)$. In fact, the mono- 
cyte count in blood has been found to be a better cross-sectional marker of plaque presence than hs-CRP, interleukin- 6 and WBC (22). Monocyte count has recently been demonstrated to be an independent predictor of future plaque formation (23). There is evidence that elastolytic cysteine proteases and their inhibitors, an important one being cystatin $\mathrm{C}$, are involved in the pathogenesis of atherosclerosis. Inflammatory cytokines associated with atherosclerosis stimulate the production of lysosomal cathepsins, and increased plasma concentrations of cystatin $\mathrm{C}$, a cathepsin inhibitor, may reflect an attempt to counterbalance a potentially damaging increased elastolytic activity. Studies have reported that human cathepsins are expressed in endothelial cells, smooth muscle cells, and macrophages, and that they are involved in the composition, the progression and the rupture of atherosclerotic plaques $(19,24)$.

On the other hand, the MedDietScore $(0-55)$ is a means to evaluate adherence to the Mediterranean diet. Higher values on the score indicate greater adherence to this pattern and, consequently, healthier dietary habits (11). Diet is considered an essential perquisite of prevention, as its impact on the development of coronary heart disease has been demonstrated by many studies so far $(25$, 26). Moreover, the athero-protective role of the Mediterranean diet is not questioned $(27,28)$.

Our finding that increases in the MedDietScore are associated with decreases in serum cystatin $\mathrm{C}$ levels could imply that adherence to the Mediterranean diet may reduce the cardiovascular risk, as assessed by cystatin $\mathrm{C}$, a prognostic marker of the cardiometabolic risk. This inverse relationship which remains significant even after adjustment for age, gender, body mass index, smoking habits, hypertension, diabetes, hypercholesterolemia, GFR, serum albumin and serum ferritin levels could have a great impact on public health. The notion that adherence to the Mediterranean diet could help to ameliorate public health in respect of cardiovascular risk, is of the utmost importance. It seems likely that we can do more to decrease our cardiometabolic risk than we have ever imagined.

\section{CONCLUSION}

In conclusion, we have demonstrated an inverse relationship regarding the MedDietScore and serum cystatin $\mathrm{C}$ levels. In other words, adherence to the Mediterranean Diet could be a simple and inexpensive method to decrease the cardiovascular risk estimated by serum cystatin $\mathrm{C}$ levels. Further large-scale studies are needed to confirm this inverse relationship which could promote public health.

\section{Acknowledgements}

Galenica SA and the Hellenic Heart Foundation funded the study (KA 00173). The authors are grateful to them and the men and women of Athens, who participated in this research. We also wish to express our gratitude to A. Giotopoulou, C. Katsagoni, E. Pagourtzi, K. Tsoutsoulopoulou, E. Serpanu, T. Rabbah, AV. Mitsopoulou (field investigators from Harokopio University and Polikliniki Hospital) for their substantial assistance in the enrollment of the participants.

\section{Conflict of Interests}

None declared

\section{REFERENCES}

1. Grubb A, Löfberg H. Human gamma-trace, a basic microprotein: amino acid sequence and presence in the adenohypophysis. Proc Natl Acad Sci U S A. 1982 May;79(9):3024-7.

2. Barrett AJ, Davies ME, Grubb A. The place of human gamma-trace (cystatin C) amongst the cysteine proteinase inhibitors. Biochem Biophys Res Commun. 1984 Apr 30;120(2):631-6.

3. Barrett AJ, Fritz H, Grubb A, Isemura S, Järvinen M, Katunuma N, et al. Nomenclature and classification of the proteins homologous with the cysteine-proteinase inhibitor chicken cystatin. Biochem J. 1986 May 15;236(1):312.

4. Simonsen O, Grubb A, Thysell $\mathrm{H}$. The blood serum concentration of cystatin $\mathrm{C}$ (gamma-trace) as a measure of the glomerular filtration rate. Scand J Clin Lab Invest. 1985 Apr;45(2):97-101.

5. Randers E, Erlandsen EJ. Serum cystatin C as an endogenous marker of the renal function - a review. Clin Chem Lab Med. 1999 Apr;37(4):389-95.

6. Abrahamson M, Olafsson I, Palsdottir A, Ulvsbäck M, Lundwall A, Jensson O, et al. Structure and expression of the human cystatin $\mathrm{C}$ gene. Biochem J. 1990 Jun 1;268(2):287-94.

7. Shlipak MG, Katz R, Sarnak MJ, Fried LF, Newman AB, Stehman-Breen $\mathrm{C}$, et al. Cystatin $\mathrm{C}$ and prognosis for cardiovascular and kidney outcomes in elderly persons without chronic kidney disease. Ann Intern Med. 2006 Aug 15;145(4):237-46.

8. Shlipak MG, Sarnak MJ, Katz R, Fried LF, Seliger SL, Newman AB, et al. Cystatin $\mathrm{C}$ and the risk of death and cardiovascular events among elderly persons. N Engl J Med. 2005 May 19;352(20):2049-60.

9. Leung-Tack J, Tavera C, Gensac MC, Martinez J, Colle A. Modulation of phagocytosis-associated respiratory burst by human cystatin C: role of the N-terminal tetrapeptide Lys-Pro-Pro-Arg. Exp Cell Res. 1990 May;188(1):16-22.

10. Bountziouka V, Bathrellou E, Giotopoulou A, Katsagoni C, Bonou M, Vallianou N, et al. Development, repeatability and validity regarding energy and macronutrient intake of a semi-quantitative food frequency questionnaire: methodological considerations. Nutr Metab Cardiovasc Dis. 2012 Aug;22(8):659-67. doi: 10.1016/j. numecd.2010.10.015.

11. Panagiotakos DB, Pitsavos C, Arvaniti F, Stefanadis C. Adherence to the Mediterranean food pattern predicts the prevalence of hypertension, hypercholesterolemia, diabetes and obesity, among healthy adults; the accuracy of the MedDietScore. Prev Med. 2007 Apr;44(4):335-40.

12. American Diabetes Association. Diagnosis and classification of diabetes mellitus. Diabetes Care. 2010;33(Suppl 1):S62-9.

13. Abrahamson M, Dalbøge H, Olafsson I, Carlsen S, Grubb A. Efficient production of native, biologically active human cystatin $\mathrm{C}$ by Escherichia coli. FEBS Lett. 1988 Aug 15;236(1):14-8.

14. Knight EL, Verhave JC, Spiegelman D, Hillege HL, de Zeeuw D, Curhan $\mathrm{GC}$, et al. Factors influencing serum cystatin $\mathrm{C}$ levels other than renal function and the impact on renal function measurement. Kidney Int. 2004 Apr;65(4):1416-21.

15. Stevens LA, Schmid CH, Greene T, Li L, Beck GJ, Joffe MM, et al. Factors other than glomerular filtration rate affect serum cystatin $\mathrm{C}$ levels. Kidney Int. 2009 Mar; 75(6):652-60.

16. Grubb A. Diagnostic value of analysis of cystatin $\mathrm{C}$ and protein $\mathrm{HC}$ in biological fluids. Clin Nephrol. 1992;38 Suppl 1:S20-7.

17. Coll E, Botey A, Alvarez L, Poch E, Quintó L, Saurina A, et al. Serum cystatin $\mathrm{C}$ as a new marker for noninvasive estimation of glomerular filtration rate and as a marker for early renal impairment. Am J Kidney Dis. 2000 Jul;36(1):29-34.

18. Muntner P, Mann D, Winston J, Bansilal S, Farkouh ME. Serum cystatin $\mathrm{C}$ and increased coronary heart disease prevalence in US adults without chronic kidney disease. Am J Cardiol. 2008 Jul 1;102(1):54-7.

19. Taglieri N, Koenig W, Kaski JC. Cystatin C and cardiovascular risk. Clin Chem. 2009 Nov;55(11):1932-43.

20. Shlipak MG, Katz R, Cushman M, Sarnak MJ, Stehman-Breen C, Psaty $\mathrm{BM}$, et al. Cystatin-C and inflammatory markers in the ambulatory elderly. Am J Med. 2005 Dec;118(12):1416.

21. Evangelopoulos AA, Vallianou NG, Bountziouka V, Katsagoni C, Bathrellou E, Vogiatzakis ED, et al. Association between serum cystatin C, monocytes and other inflammatory markers. Intern Med J. 2012 May;42(5):517-22.

22. Chapman CM, Beilby JP, McQuillan BM, Thompson PL, Hung J. Monocyte count, but not C-reactive protein or interleukin-6, is an independent risk marker for subclinical carotid atherosclerosis. Stroke. 2004 Jul;35(7):1619-24. 
23. Huang ZS, Wang CH, Yip PK, Yang CY, Lee TK. In hypercholesterolemia, lower peripheral monocyte count is unique among the major predictors of atherosclerosis. Arterioscler Thromb Vasc Biol. 1996 Feb;16(2):256-61.

24. Rodgers KJ, Watkins DJ, Miller AL, Chan PY, Karanam S, Brissette WH, et al. Destabilizing role of cathepsin $\mathrm{S}$ in murine atherosclerotic plaques. Arterioscler Thromb Vasc Biol. 2006 Apr;26(4):851-6.

25. Keys A, Menotti A, Karvonen MJ, Aravanis C, Blackburn H, Buzina R, Djordjevic BS, et al. The diet and 15-year death rate in the seven countries study. Am J Epidemiol. 1986 Dec;124(6):903-15.

26. Forman D, Bulwer BE. Cardiovascular disease: optimal approaches to risk factor modification of diet and lifestyle. Curr Treat Options Cardiovasc Med. 2006 Feb;8(1):47-57.
27. Estruch R, Martínez-González MA, Corella D, Salas-Salvadó J, RuizGutiérrez V, Covas MI, et al.; PREDIMED Study Investigators. Effects of a Mediterranean-style diet on cardiovascular risk factors: a randomized trial. Ann Intern Med. 2006 Jul 4;145(1):1-11.

28. Giugliano D, Esposito K. Mediterranean diet and cardiovascular health. Ann N Y Acad Sci. 2005 Nov;1056:253-60.

Received March 1, 2016 Accepted in revised form January 2, 2017 